\title{
Mixing and mass transfer in a pilot scale U-loop bioreactor
}

Petersen, Leander Adrian Haaning; Villadsen, John; Jørgensen, Sten Bay; Gernaey, Krist

\section{Published in:}

Biotechnology and Bioengineering

Link to article, DOI:

10.1002/bit.26084

Publication date:

2017

Document Version

Peer reviewed version

Link back to DTU Orbit

Citation (APA):

Petersen, L. A. H., Villadsen, J., Jørgensen, S. B., \& Gernaey, K. (2017). Mixing and mass transfer in a pilot scale U-loop bioreactor. Biotechnology and Bioengineering, 114(2), [344-354]. https://doi.org/10.1002/bit.26084

\section{General rights}

Copyright and moral rights for the publications made accessible in the public portal are retained by the authors and/or other copyright owners and it is a condition of accessing publications that users recognise and abide by the legal requirements associated with these rights.

- Users may download and print one copy of any publication from the public portal for the purpose of private study or research.

- You may not further distribute the material or use it for any profit-making activity or commercial gain

- You may freely distribute the URL identifying the publication in the public portal

If you believe that this document breaches copyright please contact us providing details, and we will remove access to the work immediately and investigate your claim 


\section{Mixing and mass transfer in a pilot scale U-loop bioreactor ${ }^{\dagger}$}

\section{Leander A.H. Petersen ${ }^{1,3}$, John Villadsen², Sten B. Jørgensen ${ }^{1}$, Krist V. Gernaey ${ }^{1 *}$}

1. CAPEC-PROCESS Research Centre, Department of Chemical and Biochemical Engineering, Technical University of Denmark, 2800 Lyngby, Denmark

2. CHEC Research Centre, Department of Chemical and Biochemical Engineering, Technical University of Denmark, 2800 Lyngby, Denmark

3. Unibio A/S, Billedskærevej 8, 5230 Odense, Denmark

Running title: Mixing and mass transfer in a pilot scale U-loop bioreactor

* Corresponding author:

Krist V. Gernaey

CAPEC-PROCESS Research Centre,

Department of Chemical and Biochemical Engineering

Technical University of Denmark

2800, Denmark

kvg@kt.dtu.dk

$+4545252970$

'This article has been accepted for publication and undergone full peer review but has not been through the copyediting, typesetting, pagination and proofreading process, which may lead to differences between this version and the Version of Record. Please cite this article as doi: [10.1002/bit.26084]

This article is protected by copyright. All rights reserved

Received June 3, 2016; Revision Received August 18, 2016; Accepted August 21, 2016 


\begin{abstract}
A system capable of handling a large volumetric gas fraction while providing a high gas to liquid mass transfer is a necessity if the metanotrophic bacterium Methylococcus capsulatus is to be used in single cell protein (SCP) production.

In this study mixing time and mass transfer coefficients were determined in a $0.15 \mathrm{~m}^{3}$ forced flow U-loop fermenter of a novel construction. The effect on the impeller drawn power when a gas was introduced into the system was also studied.

Mixing time decreased and mass transfer increased with increasing volumetric liquid flow rate and specific power input. This happened also for a large volume fraction of the gas, which was shown to have only minor effect on the power drawn from the pump impeller.

Very large mass transfer coefficients, considerably higher than those obtainable in an STR and previous tubular loop reactors, could be achieved in the U-loop fermenter equipped with static mixers at modest volumetric liquid and gas flow rates. This article is protected by copyright. All rights reserved
\end{abstract}

Keywords: Mixing, Mass Transfer, Power input, U-loop, Loop bioreactors, SCP

This article is protected by copyright. All rights reserved 


\section{Introduction}

The methanotrophic bacterium Methylococcus capsulatus is capable of assimilating methane and oxygen at growth rates $(\mu)$ up to $0.37 \mathrm{~h}^{-1}$ into a protein rich biomass (up to $70 \%$ of the total dry weight content) through the following reaction (Villadsen et al., 2011).

$$
\mathrm{CH}_{4}+1.45 \mathrm{O}_{2} \rightarrow 0.52 \mathrm{X}+0.48 \mathrm{CO}_{2}
$$

To utilize Methylococcus capsulatus in commercial scale production of single cell protein (SCP) it is evident from (1) that a bioreactor capable of handling a large oxygen and methane gas fraction while providing a high gas to liquid mass transfer coefficient is required.

The stirred tank reactor (STR) has been the dominant vessel of choice in the biotechnology industry since its inception (Nienow, 2014). It offers good liquid mixing as well as a decent gas-toliquid mixing in systems where the volumetric gas input is relatively modest (Nienow and Wisdom, 1974). In processes where the volumetric gas fraction becomes large compared to the total volumetric flow, it does, however, become a sub-optimal solution (Villadsen et al., 2011). As the volumetric gas fraction increases, cavities formed around the impeller reduce its ability to transfer energy into mixing and mass transfer (Nienow and Lilly, 1979). At gas volume fractions as low as 0.05 (for Rushton turbines), the impeller is flooded and as a result loses its capability to provide adequate gas hold-up and liquid pumping (Westerterp et al., 1963). For these reasons the stirred tank reactor is not a suitable vessel for Methylococcus capsulatus based SCP production.

Bubble columns and airlift fermenters are capable of handling a large volumetric flow of gas, but the absence of a device to supply an adequate mechanical energy input to the process leads to undesirably low mass transfer coefficients (Heijnen and Van’t Riet, 1984).

A system capable of handling the same volumetric gas fractions as a bubble column while still being able to supply mechanical energy on par with a mechanically stirred tank, is evidently necessary to produce SCP in large scale. Early forced flow recirculation reactors used a pump to 
transport the aqueous medium through a tubular reactor into which the gas was injected (Russell et al., 1974; Ziegler et al., 1977). In a separator exhaust gas is removed from the liquid using a hydrocyclone. The reactors were used for aerobic yeast fermentation (Russell et al., 1974; Ziegler et al., 1977).

The present paper experimentally investigates the power consumption, mixing efficiency and rate of mass transfer in a novel forced flow pilot plant fermenter $\left(0.15 \mathrm{~m}^{3}\right)$ into which static mixers are installed to provide further mass transfer than achieved in the earlier constructions. The mixing and mass transfer results will be compared to conventional bioreactor designs, and existing forced flow recirculation loop systems.

\section{Materials and methods}

The U-loop fermenter

The novel U-loop fermenter concept (Larsen, 2000) depicted in fig. 1 is also fundamentally different from existing forced flow recirculation loop systems in which the recirculation loop is used to inject liquid or gas-liquid mixtures through one or more jets into one large tank where the bioreaction takes place (Nordkvist et al., 2003). In The U-loop fermenter gas and liquid are mixed by pumping gas and liquid through a vertical U-shaped pipe (A. on fig. 1) fitted with static mixers. The U-shaped pipe leads to a cylindrical top tank (B on fig. 1) that works as a de-gassing unit. Metabolic heat is removed from the process by the installation of a pipe heat exchanger (C. on figure 1) in the loop. Essentially, the forced flow recirculation loop is turned into a near plug flow reactor for the gas phase which has a short holding time (less than one minute) versus several hours for the liquid phase. The liquid phase is radially mixed to achieve a high gas mass transfer, and its overall residence time in the U-loop reactor is determined by the desired productivity of SCP.

\section{Experimental setup}


A centrifugal pump with a high head and capable of delivering a high flow rate was chosen as pumping device in the pilot setup used in this study (1 on fig. 2). Gas was injected into the loop after the pump and the flow rate was controlled by a mass flow controller (B on fig. 2). Liquid feed is added to the system by positive displacement pumps either by injection directly into the loop or by injection into the degassing unit. Dispersion of gas and liquid was generated by static mixing elements of the SMVTM type from Sulzer (5 on fig. 2). Little data was available on the pressure drop generated by each static mixing unit and this led to the decision to use a high head pump. Temperature was kept steady at $25 \pm 0.2^{\circ} \mathrm{C}$ during all experiments by removing heat with a pipe heat exchanger (6 on fig. 2). The volumetric flow rate (Q) was measured by a flow-meter (I on fig. 2) placed in the loop. Gas was removed from the liquid in a de-gassing unit ( 7 on fig. 2) before (re)entering the pump. Pressure transmitters (A on fig. 2), temperature sensors (D on fig. 2), pH sensors (E on fig. 2) and oxygen sensors (C on fig. 2) were placed at strategic points in the loop and the exhaust pipe. The liquid volume (V) in all experiments was kept at $0.15 \mathrm{~m}^{3}$.

\section{Characterization of the U-loop fermenter}

The power input into the U-loop system is determined by the centrifugal pump transferring energy into torque. Energy transmission is consequently not fundamentally different from that transmitted into an STR, and as such power (P) and flow rate (Q) in both systems is described by the same equations (Paul et al., 2004):

$$
\begin{aligned}
& P=N_{P} \rho_{l} N^{3} D^{5} \\
& Q=N_{Q} N D^{3}
\end{aligned}
$$

Equations (2) and (3) are standard equations used to calculate the power input to an impeller (e.g a Rushton turbine) and the resulting flow away from the impeller. $\mathrm{N}$ is the rotation speed of the impeller $\left(\mathrm{s}^{-1}\right)$, D is the impeller diameter $(\mathrm{m})$ and $\rho_{1}$ is the liquid density $\left(\mathrm{kg} \cdot \mathrm{m}^{-3}\right) . \mathrm{N}_{P}$ in Eq. (2) is 
the so-called power number. It can be considered a dimensionless representation of the resistance the impeller encounters as it moves through the liquid. $\mathrm{N}_{\mathrm{Q}}$ in Eq. (3) is the dimensionless flow number and it is a measure of the impellers ability to displace liquid from one point of the U-loop fermenter to another (Paul et al., 2004).

Figure 3 shows that the measured pumping power input $(\mathrm{P})$ and volumetric flow $(\mathrm{Q})$ are directly obtained from equations (2) and (3). The slopes on the two graphs equal the dimensionless power number $\left(\mathrm{N}_{\mathrm{P}}\right)$ and flow number $\left(\mathrm{N}_{\mathrm{Q}}\right)$ respectively. Both numbers reach a constant value when the volumetric flow in the system is fully turbulent at high Reynolds numbers $(\operatorname{Re}(\mathrm{s}))$, but as the flow pattern changes from laminar to turbulent $N_{P}$ decreases slightly with increasing $\operatorname{Re}$ while $\mathrm{N}_{Q}$ increases. This phenomenon explains why neither of the two lines intersects at the origin. Only turbulent flows at impeller Reynolds numbers ranging from $8.94 \cdot 10^{5}-2.25 \cdot 10^{6}$ were studied in this paper, which is why a more traditional plot showing the power number and flow number versus the Reynolds number is not included.

When a gas is introduced into the system, the only change in power and flow originates from the pump's ability to handle different density liquids or gas/liquid mixtures. Consequently, when aerating the system only the dimensionless power number $\left(\mathrm{N}_{\mathrm{P}}\right)$ and flow number $\left(\mathrm{N}_{\mathrm{Q}}\right)$ undergo a slight change to form (4) and (5).

$$
\begin{aligned}
& P_{g}=N_{P, g} \rho_{l} N^{3} D^{5} \\
& Q_{G}=N_{Q, g} N D^{3}
\end{aligned}
$$

The dimensionless parameters $\mathrm{N}_{\mathrm{P}, \mathrm{g}}$ and $\mathrm{N}_{\mathrm{Q}, \mathrm{g}}$ in Eq. (4) and (5) represent the modified (gassed) power and flow number respectively, when a gas is introduced into the system.

Considering that all data is gathered with industrial equipment, and that small forces such as friction in the smooth pipe are neglected, the agreement between experimental data and the fundamental equations (2-5) is remarkably good. 
In stirred tank reactor systems it is desired to compare the decrease in power input when a gas is introduced into the system and the resulting ability of the impeller to mix gas and liquid, i.e. to provide mass transfer. This is done by introducing the aeration number (6) (Calderbank, 1958; Nienow, 2014; Paul et al., 2004; Villadsen et al., 2011).

$$
N_{A}=Q_{g} N^{-1} D^{-3}
$$

Gas is injected after the pump impeller into the U-loop fermenter, and if complete degassing of the liquid in the degasser is assumed, then it is the liquid flow acting on the gas bubbles that creates aeration, not the rotations of the pump impeller itself. With this in mind, it is possible to describe aeration in the U-loop through a slight alteration of (6):

$$
N_{A}=Q_{g} N_{Q, g}^{-1} N^{-1} D^{-3}
$$

Eq. (7) also accounts for situations where the gravitational forces exerted on the gas bubbles exceed the torque exerted by the pump. In this case the aeration number would be zero despite a gas flow and rotation of the impeller, as all the gas escapes directly to the degassing unit. Eq. (7) makes it possible to compare the U-loop fermenters ability to handle gas with that of a stirred tank reactor.

\section{Model fluids}

Fermentation broths with Methylococcus capsulatus cell densities of up to $20 \mathrm{~g} \cdot \mathrm{L}^{-1} \mathrm{did}$ not exhibit viscosities measurably different from that of water. To mimic the fermentation broth we used a non-coalescing solution with little to no buffer capacity (to avoid interference with the mixing time experiments) and oxygen solubility similar to that of water. A 0.05 M Potassium Chloride (KCl) solution (Marrucci and Nicodemo, 1967) was used in all experiments and found to satisfactorily meet the above-mentioned demands. 


\section{Mixing}

Mixing time in bioreactors can be quantified by observing the shift in $\mathrm{pH}$ after injecting a tracer slug of concentrated acid or base, as long as the change in $\mathrm{pH}$ is modest, and any present buffer systems are inactive (Nordkvist et al., 2003; Villadsen et al., 2011). pH was monitored with a frequency of $1 \mathrm{~s}^{-1}$ with two electrodes placed at strategic points in the loop (E on fig. 2). For each $\mathrm{pH}$ measurement a normalized $\mathrm{pH}$ was calculated according to (8).

$$
E=\left|\left(p H(t)-p H_{\text {final }}\right)\left(p H_{\text {final }}-p H_{\text {initial }}\right)^{-1}\right|
$$

Two different mixing processes were investigated.

- Mixing by leg-injection: The tracer slug was introduced to the system between the pump (1 on fig. 2) and the static mixing device (5 on fig. 2). Here significant mixing is only achieved through recirculation over the static mixers.

- Mixing by top tank injection: The tracer was introduced to the system in the degassing unit (7 on fig. 2). Mixing is already achieved by turbulence in the degassing unit, and further through recirculation over the static mixers.

Several different acid/base concentrations were tested ranging from 1-10 M. A $5 \mathrm{ml}$ addition of $2 \mathrm{M}$ HNO3 or $2 \mathrm{M} \mathrm{NaOH}$ over a 4 second time period gave a satisfactory final $\mathrm{pH}$ step of $0.1-0.3 \mathrm{pH}$ units, as well as a very smooth first order normalized pH profile (Marten et al., 1997) in agreement with (9) in the leg mixing experiments.

$$
E=e^{-k_{m i x} t}
$$

The time required to reach a specific degree of mixing $(\mathrm{m})$ follows from (10). 
$t_{m i x, m}=-k_{m i x}^{-1} \ln (1-m)$

In the experiments where a tracer was added to the degassing unit, mixing depends on the level of turbulence in the degasser, as well as on distribution through the loop pipe. Consequently mixing cannot be described by a single rate constant as in (9) and (10). The time to achieve a specific degree of mixing was instead calculated as the time interval between the initial responses in the normalized $\mathrm{pH}$ profile and a mixing degree of $m$ (Nordkvist et al., 2003).

The mixing time was determined as the average value of at least four individual measurements with each tracer, performed for each set of operating conditions, as addition of an alkaline tracer gives a slight overestimation of the mixing time while addition of acid results in an underestimation (Nordkvist et al., 2003). Using data from either $\mathrm{pH}$ probe resulted in less than a $2 \%$ deviation in the mixing time. Consequently only one result (the average value) was reported.

\section{Mass Transfer}

Gas-liquid mass transfer coefficients were obtained using the hydrogen peroxide steady state technique (Hickman, 1988). Initially catalase (Catazyme ${ }^{\circledR}$ from Novozymes A/S) was added to the $0.05 \mathrm{M} \mathrm{KCl}$ solution in the U-loop. After testing several catalase concentrations ranging from 10$100 \mathrm{~g} \cdot \mathrm{m}^{-3}$, a concentration of $\geq 70 \mathrm{~g} \cdot \mathrm{m}^{-3}$ was found to be non-rate limiting, and deemed satisfactory. Additional catalase was supplied every hour and during each steady state. This was done to compensate for loss of catalytic activity, and to ensure that the enzymatic reaction was not limiting.

Figure 4 shows a typical experiment. A steady state oxygen tension (measured with two Mettler Toledo InPro ${ }^{\circledR}$ 6860i sensors positioned at $\mathrm{C}$ in fig. 2) was obtained at a specific volumetric gas flow rate and specific power input. A constant flow rate (measured with a flow-meter) of a $\mathrm{H}_{2} \mathrm{O}_{2}$ mixture was then injected into the leg of the U-loop fermenter by a positive displacement 
pump ( 3 on fig. 2). Based on the mixing time experiments a $2.65 \mathrm{M} \mathrm{H}_{2} \mathrm{O}_{2}$ solution (determined by titration with $\mathrm{KMnO}_{4}$ ) was chosen.

A new steady state in the oxygen tension was reached, and kept for approximately 30 min. Addition of $\mathrm{H}_{2} \mathrm{O}_{2}$ was then stopped, and it was ensured that the oxygen tension returned to the initial value. Assuming that the liquid phase is perfectly mixed one determines the gas/liquid mass transfer coefficient $\left(k_{L} a\right)$ from (11).

$k_{L} a=\frac{Q_{H 2 O 2}\left[H_{2} O_{2}\right]}{2 V c_{l}^{*}\left(p O_{2} / p O_{2}^{\text {sat }}-1\right)}$

$c_{1}{ }^{*}$ is the saturation concentration of the oxygen in the liquid. Under the assumption that complete back mixing of the gas phase occurs, this can be determined by (12)

$c_{l}^{*}=\frac{p_{O_{2}}^{\text {exit }}}{H_{O}} p$

In Eq. 12, $\mathrm{p}_{\mathrm{O} 2}{ }^{\text {exit }}$ is the volume fraction of oxygen in the gas leaving the system during each steady state, $\mathrm{H}_{\mathrm{O}}$ is henry's constant for oxygen in water at $\mathrm{T}=25^{\circ} \mathrm{C}\left(7.69 \cdot 10^{4} \mathrm{~m}^{3} \cdot \mathrm{Pa} \cdot \mathrm{mol}^{-1}(\right.$ Sander, 2015)) and $\mathrm{p}$ is the pressure measured at the oxygen sensor (to account for hydrostatic pressure changes). Aeration did not affect the gauge pressure at the oxygen sensor. Eq. 12 assumes that the gas phase is well mixed. This assumption was found to be sufficient in this study, as using data from either oxygen sensor resulted in less than a $3 \%$ deviation in the mass transfer coefficient calculated using Eq. 11 and Eq. 12. Consequently only one result (the average value) was reported. Steady state oxygen tension was unaffected by the supply of additional catalase, ruling out the enzymatic reaction being rate limiting. In larger U-loop fermenters, a different model for the gas phase (i.e. a plug flow model) might be necessary. 
The specific power input $(\mathrm{P} / \mathrm{V})$ was varied from $7500-29000 \mathrm{~W} \cdot \mathrm{m}^{-3}$ and the volumetric gas flow rate $\left(\mathrm{Q}_{\mathrm{g}}\right)$ ranged from $2.83 \cdot 10^{-4}$ to $1.43 \cdot 10^{-3} \mathrm{~N} \cdot \mathrm{m}^{3} \cdot \mathrm{s}^{-1}$.

\section{Results and discussion}

\section{Power and flow}

Table I shows a selection of power numbers $\left(\mathrm{N}_{\mathrm{P}}\right.$ and $\left.\mathrm{N}_{\mathrm{P}, \mathrm{g}}\right)$ and flow numbers $\left(\mathrm{N}_{\mathrm{Q}}\right.$ and $\left.\mathrm{N}_{\mathrm{Q}, \mathrm{g}}\right)$ at given aeration numbers $\left(\mathrm{N}_{\mathrm{A}}\right)$ found using Eq. (2)-(7). Notable from Table I is that although the power numbers for the impeller in the centrifugal pump are relatively small compared to traditional impellers (Nienow and EKATO, 2000) so are the flow numbers. The centrifugal pump used in this study was for other reasons over designed to overcome a pressure loss $(\Delta p)$ over the U-shaped pipe of up to $4 \cdot 10^{5} \mathrm{~Pa}$. The ability to overcome a drop in gauge pressure by a centrifugal pump is accomplished through the conversion of kinetic flow energy into localized turbulence in and around the pump casing by the insertion of resistance generating devices (Grundfos, 2014). As such the high lifting capabilities of the pump form a direct explanation of the low flow numbers.

Another interesting observation from Table I is that only minor changes in power and flow number take place as the aeration number increases. Conducting a more in-depth study of the power number as a function of the aeration number for the U-loop fermenter and a STR (shown in figure 5.) reveals that a unique relationship between power transferred into mixing and volumetric gas flow exists in the U-loop fermenter. In the STR, power drawn from the impeller seems to decease drastically with increased volumetric gas flow, while it appears that this drop is almost non-existing in the U-loop.

Dependent on the number of impellers, the traditional STR is flooded when the volumetric gas fraction reaches 0.055 and 0.11 respectively (Nienow and Lilly, 1979). In the U-loop gas-toliquid mixing occurs at volumetric gas fractions up to 0.27 without flooding. Depending on the number of impellers this is potentially a fivefold increase in how much gas can be mixed into the liquid. 
Furthermore at aeration numbers between 0.055 and 0.11 ; the decrease in power drawn from the pump impeller in the U-loop fermenter was barely measurable, compared to a drop to 0.49 (in the one Rushton turbine STR at $\mathrm{N}_{\mathrm{A}}=0.055$ ) and 0.62 (in the 2 Rushton turbine STR at $\mathrm{N}_{\mathrm{A}}=0.11$. This means that the reduction in power drawn from the pump impeller is $0.1 \%$ in the U-loop fermenter when a gas is introduced into the system. This number is about 500 times higher in a traditional STR equipped with one Rushton turbine, and about 380 times higher in a traditional STR equipped with two Rushton impellers. Even at aeration numbers as high as 0.27 , the power number in the U-loop fermenter only decreases from 1 to about 0.97 , which is about 13 times less power lost compared to a 2 Rushton turbine STR at less than half the level of aeration.

Gas enters the U-loop fermenter after the pump, and exits the reactor in the degassing unit before the liquid reenters the pump casing. This ingenious design evidently leads to a constant drawn power from the impeller, as gas, apart for the small fraction soluble in the liquid medium is never present around the impeller blade.

\section{Mixing}

Mixing times $\left(\mathrm{t}_{\mathrm{mix}, 95 \%)}\right.$ ranged from around 600-160 seconds when injecting a tracer into the leg, and from around 140-35 seconds when the tracer slug was introduced through the degassing unit. Mixing time could be correlated to volumetric flow and specific power input through (13) and (14) respectively for mixing by leg injection.

$$
\begin{aligned}
& t_{\text {mix }, 95 \%}=0.3295 Q^{-1.413} \\
& t_{m i x, 95 \%}=613000(P / V)^{-0.801}
\end{aligned}
$$

And through (15) and (16) for mixing by top tank injection (=injection in the degasser)

$$
t_{\text {mix }, 95 \%}=0.0567 Q^{-1.539}
$$


$t_{m i x, 95 \%}=755000(P / V)^{-0.941}$

A detailed presentation of the mixing time data is shown in figure 6. The mixing time is evidently much shorter if the tracer is introduced into the degasser instead of directly into the U-shaped pipe. This is not surprising when the magnitude of turbulence in the degassing unit is taken into consideration.

The rather long mixing time when introducing the tracer in the leg, indicates a low extent of mixing, which is consistent with the nearly ideal plug flow conditions one would expect locally in the U-shaped part of the fermentor.

For the purpose of single cell protein production, where the primary nutrients $\left(\mathrm{CH}_{4}\right.$ and $\left.\mathrm{O}_{2}\right)$ have to be transferred from the gas phase to the liquid phase, and only trace concentrations of minerals need to be blended from a continuous liquid feed, the mixing times measured in this study are entirely satisfactory for both types of mixing.

While equation (13) and (15) show that an adequate degree of mixing is achieved at modest volumetric flows, equation (14) and (16) indicate that a large power input is required. During experiments the pressure drop recorded at point A on fig. 2 was less than $1 \cdot 10^{5} \mathrm{~Pa}$. Localized turbulence would logically not provide any beneficial effect on the mixing time (or mass transfer) in the U-loop system as a whole, which means that an unnecessarily large power input is wasted in the pump casing. A selection of a pump with a more suitable head will be beneficial for future designs, and lead to a significant decrease in energy expenditure to achieve desired mixing times.

\section{Mass Transfer}

Gas-to-liquid mass transfer coefficient $\left(\mathrm{k}_{\mathrm{L}}\right.$ a) values ranged from 400-3000 $\mathrm{h}^{-1}$ and could through a least square regression be correlated to the superficial gas velocity $\left(\mathrm{u}_{\mathrm{g}}\right)$, the volumetric flow and specific power input through (17) and (18) respectively. 
$k_{L} a=471 Q_{G}^{0.862} u_{g}^{0.822}$

$k_{L} a=103\left(P_{g} / V\right)^{0.482} u_{g}^{0.824}$

In Eq. (17) and (18) $\mathrm{k}_{\mathrm{L}}$ a is in $\mathrm{h}^{-1}$, and $\mathrm{Q}_{\mathrm{G}}$ is in $\mathrm{m}^{3} \mathrm{~h}^{-1}$ while all other parameters are in SI units. A detailed presentation of the mass transfer data is shown in figure 7. The mass transfer values are extraordinarily high for a vessel of the size used in this study. While equation (17) shows that a large mass transfer coefficient can be achieved at modest volumetric flows and superficial gas velocities, equation (18) indicates that a very large power input is required. This result is similar to the observations made in the previous section. If another centrifugal pump was used with the same impeller, capable of delivering the same volumetric flow, but with a different casing enabling it to overcome a gauge pressure loss of $1.5 \cdot 10^{5} \mathrm{~Pa}(50 \%$ more than the highest value measured in this study) instead of $4 \cdot 10^{5} \mathrm{~Pa}$, a threefold reduction in power input could be expected (SANWA, private communication).

For an STR where the height $(H)$ equals the diameter $\left(D_{v}\right)$, the gas to liquid mass transfer coefficient can be expressed by (19) (Van't Riet, 1979).

$k_{L} a=93.6(P / V)^{0.4} u_{g}^{0.5}$

If the height $(\mathrm{H})$ is twice the diameter $\left(\mathrm{D}_{\mathrm{v}}\right)$, the gas to liquid mass transfer in an STR follows (20) (Vasconcelos et al., 2000).

$k_{L} a=22.3(P / V)^{0.66} u_{g}^{0.51}$

A comparison between Eq. (18), (19) and (20) is shown in figure 8 (A-D). Figures A and B show that with the high head centrifugal pump, the performance of the U-loop fermenter is similar to an STR with $H=D_{v}$ and the mass transfer is in fact better in an STR with $H=2 D_{v}$ if all vessels are This article is protected by copyright. All rights reserved 
aerated with the same superficial gas velocity. However if a more suitable centrifugal pump capable of overcoming a smaller pressure loss $\left(1.5 \cdot 10^{5} \mathrm{~Pa}\right.$ instead of $\left.4 \cdot 10^{5} \mathrm{~Pa}\right)$ is used, the U-loop fermenter with $u_{g} \geq 0.15 \mathrm{~ms}^{-1}$ starts outperforming conventional systems, even at modest power inputs.

When looking at the data one must not forget that the design of the U-loop fermenter allows very high superficial gas velocities to be achieved at very modest volumetric gas flow rates; for example aerating a $0.15 \mathrm{~m}^{3} \mathrm{U}$-loop fermenter with $1 \mathrm{vvm}$ achieves the same superficial gas velocity as an $0.15 \mathrm{~m}^{3}$ STR with $\mathrm{H}=2 \mathrm{D}_{\mathrm{v}}$ aerated with $\sim 17.3 \mathrm{vvm}$ and an $0.15 \mathrm{~m}^{3} \mathrm{STR}$ with $\mathrm{H}=\mathrm{D}_{\mathrm{v}}$ aerated with $\sim 27.4 \mathrm{vvm}$. Aerating a $0.15 \mathrm{~m}^{3} \mathrm{STR}$ with such high volumetric gas flow would lead to flooding unless a massive energy input is transmitted to the mixing aggregate. Figure $8(\mathrm{C}$ and $\mathrm{D})$ shows that much higher $\mathrm{k}_{\mathrm{L}}$ a values than those of STRs can be achieved in the U-loop fermenter at similar volumetric gas flow rates and even with the pump used in this study. In an STR the liquid phase is more or less considered to be well mixed, but the gas phase is neither well mixed nor in plug flow through the liquid (unless the gas hold up is very small). In the U-loop reactor the gas and liquid follow each other in plug flow, Due to the long hold up time of the liquid the concentrations in the liquid phase are almost constant throughout the loop, but the gas phase loses reactants $\mathrm{O}_{2}$ and $\mathrm{CH}_{4}$ as in a plug flow reactor (i.e. by first order reaction kinetics) as soon as the process becomes limited by mass transfer by the continuously decreasing $\mathrm{c}_{1}{ }^{*}$.

The mass transfer values found in this study are much higher than the ones found in previous studies of similar systems (Ziegler et al., 1977). Earlier tubular loop reactors were not equipped with static mixing devices and relied solely on gas holdup and turbulence to generate mass transfer. Evidently the static mixing devices used in this study facilitate an exceptionally high interfacial area " $\mathrm{a}$ " as $\mathrm{k}_{\mathrm{L}}$ is not expected to change.

For an STR where the impeller is replaced with a forced flow recirculation loop, and mixing/mass transfer is facilitated by allowing gas/liquid from the loop to pass through a rotary jet head, the gas-liquid mass transfer coefficient can be expressed by (21) (Nordkvist et al., 2003). 
$k_{L} a=345 Q^{0.700} u_{g}^{0.764}$

The system is very similar to the one investigated in this study, and Eq. (17) is strikingly similar to (21). The U-loop fermenter does however outperform the rotary jet heads as is evident in figure 9. This can probably be attributed to a larger gas-volume fraction in the loop part of the U-loop fermenter, and the good performance generally noted for static mixing devices.

\section{Conclusion}

The U-loop fermenter evidently handles the process requirement for a large volumetric gas fraction quite well. The ingenious design of introducing gas into the system after the pump and stripping it before the liquid re-enters the pump casing, results in little or no difference between the gassed and un-gassed power numbers, even at high volumetric gas fractions and aeration numbers.

Mixing times of 600-35 seconds which satisfied the process demands and very high mass transfer coefficients of 400-3000 $\mathrm{h}^{-1}$ could be achieved at modest volumetric flow rates within the experimental range of $6.95 \cdot 10^{-3}-1.41 \cdot 10^{-2} \mathrm{~m}^{3} \cdot \mathrm{s}^{-1}$ studied. The design of the U-loop allowed for high superficial gas velocities to be achieved at modest volumetric gas flow rates, which meant that the system still outperformed a traditional stirred tank even with the over-dimensioned pump used in this study.

Proper dimensioning of the pump proved to be of utmost importance as a pump with a larger head than needed leads to an unnecessarily large power input requirement $\left(7500-29000 \mathrm{~W} \cdot \mathrm{m}^{-3}\right)$ to achieve mixing and mass transfer.

As mixing time and mass transfer were correlated to the drawn power input at a constant volume $\left(\mathrm{V}=0.15 \mathrm{~m}^{3}\right)$ it would be highly interesting to investigate whether these equations apply to other reactor volumes outside the experimental range used in this study. 


\section{Nomenclature}

\section{Notation}

Symbol name unit

$\mathrm{c}_{1}{ }^{*} \quad$ Oxygen saturation $\mathrm{mol} \cdot \mathrm{m}^{-3}$

D Impeller diameter m

$\begin{array}{lll}\mathrm{D}_{\mathrm{v}} & \text { Tank Diameter } & \mathrm{m}\end{array}$

E $\quad$ Normalized $\mathrm{pH}$

$\begin{array}{lll}\mathrm{H} & \text { Liquid height }\end{array}$

$\mathrm{H}_{\mathrm{O}} \quad$ Henrys constant for oxygen in water at $25^{\circ} \mathrm{C} \quad \mathrm{m}^{3} \cdot \mathrm{Pa} \cdot \mathrm{mol}^{-1}$

$\left[\mathrm{H}_{2} \mathrm{O}_{2}\right] \quad$ Feed concentration of hydrogen peroxide $\mathrm{mol} \cdot \mathrm{m}^{-3}$

$\mathrm{k}_{\mathrm{L}} \mathrm{O} \quad$ Oxygen mass transfer coefficient $\quad \mathrm{h}^{-1}$

$\mathrm{k}_{\text {mix }} \quad$ Mixing constant $\quad \mathrm{s}^{-1}$

m Degree of mixing

$\mathrm{N} \quad$ Rotations of the impeller $\quad \mathrm{rps}\left(\mathrm{s}^{-1}\right)$

$\mathrm{N}_{\mathrm{A}} \quad$ Aeration number

$\mathrm{N}_{\mathrm{P}} \quad$ Power number

$\mathrm{N}_{\mathrm{P}, \mathrm{g}} \quad$ Gassed power number

$\mathrm{N}_{\mathrm{Q}} \quad$ Flow number

$\mathrm{N}_{\mathrm{Q}, \mathrm{g}} \quad$ Gassed flow number

\begin{tabular}{l|l}
$\mathrm{P}$ & Drawn power
\end{tabular}

$\mathrm{P}_{\mathrm{g}} \quad$ Gassed drawn power $\quad \mathrm{W}$

$\begin{array}{lll}\mathrm{p} & \text { Gauge pressure } & \mathrm{Pa}\end{array}$

$\mathrm{pO}_{2} \quad$ Dissolved oxygen tension $\%$

$\mathrm{pO}_{2}{ }^{\text {exit }} \quad$ Oxygen volume fraction in exhaust gas $\%$

$\mathrm{pO}_{2}{ }^{\text {sat }} \quad$ Dissolved oxygen tension at saturation $\%$

Q Volumetric liquid flow rate $\mathrm{m}^{3} \cdot \mathrm{s}^{-1}$

This article is protected by copyright. All rights reserved 


\begin{tabular}{|c|c|c|}
\hline $\mathrm{Q}_{\mathrm{H} 2 \mathrm{O} 2}$ & Volumetric feed flow rate of $\mathrm{H} 2 \mathrm{O} 2$ & $\mathrm{~m}^{3} \cdot \mathrm{h}^{-1}$ \\
\hline $\mathrm{Q}_{\mathrm{g}}$ & Volumetric gas flow rate & $\mathrm{m}^{3} \cdot \mathrm{s}^{-1}$ \\
\hline $\mathrm{Q}_{\mathrm{G}}$ & Gassed Volumetric liquid flow rate & $\mathrm{m}^{3} \cdot \mathrm{s}^{-1}$ \\
\hline $\mathrm{Re}$ & Reynolds number & \\
\hline STR & Stirred tank reactor & \\
\hline $\mathrm{T}$ & Temperature & ${ }^{\circ} \mathrm{C}$ \\
\hline $\mathrm{t}$ & Time & $\mathrm{s}$ \\
\hline $\mathrm{t}_{\text {mix }}$ & Mixing time $(95 \%)$ & $\mathrm{s}$ \\
\hline $\mathrm{u}_{\mathrm{g}}$ & Superficial gas velocity & $\mathrm{m} \cdot \mathrm{s}^{-1}$ \\
\hline $\mathrm{V}$ & Volume & $\mathrm{m}^{3}$ \\
\hline vvm & Volume gas pr. volume liquid pr. minute & $\mathrm{m}^{3} \cdot \min ^{-1} \cdot \mathrm{m}^{-3}$ \\
\hline $\mathrm{X}$ & stoichiometric symbol for biomass & \\
\hline
\end{tabular}

\section{Greek letters}

$\Delta \mathrm{p} \quad$ Gauge pressure difference $\quad \mathrm{Pa}$

$\mu$

Specific growth rate

$\mathrm{h}^{-1}$

$\rho_{1}$

Liquid density

$\mathrm{kg} \cdot \mathrm{m}^{-3}$ 


\section{References}

Calderbank PH. 1958. Physical rate processes in industrial fermentation. I. Trans. Inst. Chem. Engrs. 36:443-463.

Grundfos. 2014. Pump Handbook:1747-1749.

Heijnen JJ, Van't Riet K. 1984. Mass transfer, mixing and heat transfer phenomena in low viscosity bubble column reactors. Chem. Eng. J. 28:B21-B42.

Hickman AD. 1988. Gas-liquid oxygen transfer and scale-up. A novel experimental technique with results for mass transfer in aerated agitated vessels. In: . Proc. 6th Eur. Conf. Mix., pp. 369374.

Larsen EB. 2000. U-shape and/or nozzle-u-loop fermentor and method of carrying out a fermentation process. World Intellectual Property Organization WO2000070014.

Marrucci G, Nicodemo L. 1967. Coalescence of gas bubbles in aqueous solutions of inorganic electrolytes. Chem. Eng. Sci. 22:1257-1265.

Marten MR, Wenger KS, Khan SA. 1997. Rheology, Mixing Time, and Regime Analysis for a Production-Scale Aspergillus oryzae Fermentation. 4th Int. Symp. Bioreact. Bioprocess Fluid Dyn.:295-313.

Nienow AW, Lilly MD. 1979. Power drawn by multiple impellers in sparged agitated vessels. Biotechnol. Bioeng. 21:2341-2345.

Nienow AW, Wisdom DJ. 1974. Flow over disc turbine blades. Chem. Eng. Sci. 29:1994-1997.

Nienow AW, EKATO. 2000. EKATO handbook of mixing technology. Schopfheim (All.): EKATO Rühr.

Nienow AW. 2014. Stirring and stirred-tank reactors. Chemie-Ingenieur-Technik 86:2063-2074.

Nordkvist M, Grotkjær T, Hummer JS, Villadsen J. 2003. Applying rotary jet heads for mixing and 
mass transfer in a forced recirculation tank reactor system. Chem. Eng. Sci. 58:3877-3890.

Paul EL, Atiemo-Obeng VA, Kresta SM. 2004. Handbook of industrial mixing: science and practice. John Wiley \& Sons.

Russell TWF, Dunn IJ, Blanch HW. 1974. The tubular loop batch fermentor: Basic concepts. Biotechnol. Bioeng. 16:1261-1272.

Sander R. 2015. Compilation of Henry's law constants (version 4.0) for water as solvent. Atmos. Chem. Phys. 15:4399-4981.

Van't Riet K. 1979. Review of Measuring Methods and Results in Nonviscous Gas-Liquid Mass Transfer in Stirred Vessels. Ind. Eng. Chem. Process Des. Dev. 18:357-364.

Vasconcelos JMT, Orvalho SCP, Rodrigues AM a. F, Alves SS. 2000. Effect of Blade Shape on the Performance of Six-Bladed Disk Turbine Impellers. Ind. Eng. Chem. Res. 39:203-213.

Vasconcelos JMT, Alves SS, Nienow AW, Bujalski W. 1998. Scale-up of mixing in gassed multiturbine agitated vessels. Can. J. Chem. Eng. 76:398-404.

Villadsen J, Nielsen JH, Lidén G. 2011. Bioreaction Engineering Principles 3rd ed. Springer US.

Westerterp KR, van Dierendonck LL, de Kraa JA. 1963. Interfacial areas in agitated gas-liquid contactors. Chem. Eng. Sci. 18:157-176.

Ziegler H, Meister D, Dunn IJ. 1977. The tubular loop fermentor: oxygen transfer, growth kinetics, and design. Biotechnol. Bioeng. 19:507-525. 
Table I: A selection of power numbers $\left(\mathrm{N}_{\mathrm{p}}\right)$, gassed power numbers $\left(\mathrm{N}_{\mathrm{p}, \mathrm{g}}\right)$, flow numbers $\left(\mathrm{N}_{\mathrm{Q}}\right)$, gassed flow numbers $\left(\mathrm{N}_{\mathrm{Q}, \mathrm{g}}\right)$ found during experiments in the $0.15 \mathrm{~m}^{3} \mathrm{U}$-loop fermenter at increasing aeration numbers $\left(\mathrm{N}_{\mathrm{A}}\right)$.

\begin{tabular}{ccc}
\hline $\mathbf{N}_{\mathbf{P}} / \mathbf{N}_{\mathbf{P g}}$ & $\mathbf{N}_{\mathbf{A}}$ & $\mathbf{N}_{\mathbf{Q}} / \mathbf{N}_{\mathbf{Q}, \mathbf{g}}$ \\
\hline 0.2009 & 0.0000 & 0.0043 \\
0.2009 & 0.0200 & 0.0042 \\
0.2004 & 0.0410 & 0.0041 \\
0.1994 & 0.0605 & 0.0043 \\
0.1981 & 0.0938 & 0.0042 \\
0.1975 & 0.1012 & 0.0044 \\
0.1989 & 0.1207 & 0.0043 \\
0.1967 & 0.1661 & 0.0044 \\
0.1946 & 0.1988 & 0.0045 \\
0.1939 & 0.2438 & 0.0046 \\
\hline
\end{tabular}

This article is protected by copyright. All rights reserved 


\section{Figures:}

Figure 1: Illustration of the U-loop concept. (A) Degassing unit, (B) U-shaped pipe, (1) placement of pump, (2) inlet for gasses and minerals, (3) static mixing elements, (4) heat exchanger for removal of metabolic heat, (5) gas outlet.

Figure 2: Process diagram for the experimental setup used in this study. (A) gauge pressure transmitter, (B) gas mass flow controller, (C) dissolved oxygen sensor, (D) temperature transmitter, (E) pH transmitter, (I) flow meter, (V) sanitary membrane valve, (1) centrifugal pump, (2) container(s) for Acid $(2 \mathrm{M} \mathrm{HNO}$ ), Base (2M NaOH) and $\mathrm{H}_{2} \mathrm{O}_{2},(3)$ positive displacement pump(s), (4) gas compressor, (5) static mixing elements, (6) pipe heat exchanger, (7) degasser.

Figure 3: (Top) power $(P)$ as a function of the liquid density $\left(\rho_{1}\right)$, the impeller rotation $(N)$ to the power of three, and the impeller diameter (D) to the power of five. (Bottom) volumetric flow (Q) as a function of the impeller rotation $(N)$ and impeller diameter $(D)$ to the power of three. A linear fit with a slope equal to the power number $\left(\mathrm{N}_{\mathrm{P}}\right)$ (top) and flow number $\left(\mathrm{N}_{\mathrm{Q}}\right)$ (bottom) can be achieved when the liquid flow is turbulent.

Figure 4: Typical mass transfer experiment using the $\mathrm{H}_{2} \mathrm{O}_{2}$ method in an aqueous medium at $25^{\circ} \mathrm{C}$. The steady-state oxygen tension was $25 \%$ higher than when no peroxide was added. Catalase was added during steady state at $t=50 \mathrm{~min}$, and by the end of the experiment at $t=100 \mathrm{~min}$. The steady state oxygen tension is unaffected by additional enzyme.

Figure 5: The decrease in power number relative to the un-gassed power number $\left(\mathrm{N}_{\mathrm{p}, \mathrm{g}} / \mathrm{N}_{\mathrm{P}}\right)$ depicted as a function of the aeration number $\left(\mathrm{N}_{\mathrm{A}}\right) .(\bullet)$ Data from the $0.15 \mathrm{~m}^{3}$ The U-loop fermenter used in this study,

$(\square)$ STR with two $D=0.19 \mathrm{~m}$ Rushton turbines (Nienow and Lilly, 1979), $(\Delta)$ STR with one $D=0.19$ m Rushton turbine (Nienow and Lilly, 1979).

Figure 6: Mixing time data from the mixing by leg injection $(\Delta)$ and top tank injection $(\diamond)$ experiments, correlated versus the specific power input (P/V) (top) and volumetric flow (Q) (bottom) respectively.

Figure 7: Mass transfer $\left(\mathrm{k}_{\mathrm{L}} \mathrm{a}\right)$ data $(\Delta)$. (Top) $\mathrm{k}_{\mathrm{L}}$ a correlated versus the specific power input $\left(P_{g} / V\right)$ and superficial gas velocity $\left(\mathrm{u}_{\mathrm{q}}\right)$. (Bottom) $\mathrm{k}_{\mathrm{L}}$ a correlated versus the volumetric flow $\left(\mathrm{Q}_{\mathrm{G}}\right)$ superficial gas velocity $\left(u_{a}\right)$.

Figure 8: ( $A$ and $B$ ) Comparison of the mass transfer coefficients $\left(k_{L} a\right)$ for the $0.15 \mathrm{~m}^{3} \mathrm{U}$-loop fermenter and mechanically stirred systems at 2 different superficial gas velocities $\left(u_{g}\right.$ ) equal to $0.06 \mathrm{~m} \cdot \mathrm{s}^{-1}$ and $0.15 \mathrm{~m} \cdot \mathrm{s}^{-1}$.

(a) the U-loop fermenter (Eq. (18)), (d) STR Eq. (20) with H=2Dv (Vasconcelos et al., 1998), (b) STR Eq. (19) with $H=D_{v}$ (Van't Riet, 1979), (c) predicted curve for a U-loop fermenter if a centrifugal pump with a lower head is used ( 3 times smaller motor). ( $C$ and $D)$ Comparison of the mass transfer coefficients $\left(k_{L} a\right)$ for the $0.15 \cdot \mathrm{m}^{3} \mathrm{U}$-loop fermenter and mechanically stirred systems at 2 different volumetric gas flow rates ( $\mathrm{Q}_{\mathrm{g}}$ ) equal to $0.67 \mathrm{vvm}$ and $1.33 \mathrm{vvm}$. (a) the U-loop fermenter (Eq. (18)), (d) STR Eq. (20) with H=2Dv (Vasconcelos et al., 1998), (b) STR Eq. (19) with $H=D_{v}$ (Van't Riet, 1979).

Figure 9: (A-D) Comparison of the mass transfer coefficients $\left(k_{L} a\right)$ for the $0.15 \mathrm{~m}^{3} \mathrm{U}$-loop fermenter and a system where mixing is created by a forced flow circulation loop through a rotary jet head, at four different superficial gas velocities $\left(\mathrm{u}_{\mathrm{g}}\right)$ ranging from $0.06-0.15 \mathrm{~m} \cdot \mathrm{s}^{-1}$. (a) the U-loop fermenter (Eq. (18)) and (b) RJH Eq. (21) (Nordkvist et al., 2003).

This article is protected by copyright. All rights reserved 
(A)

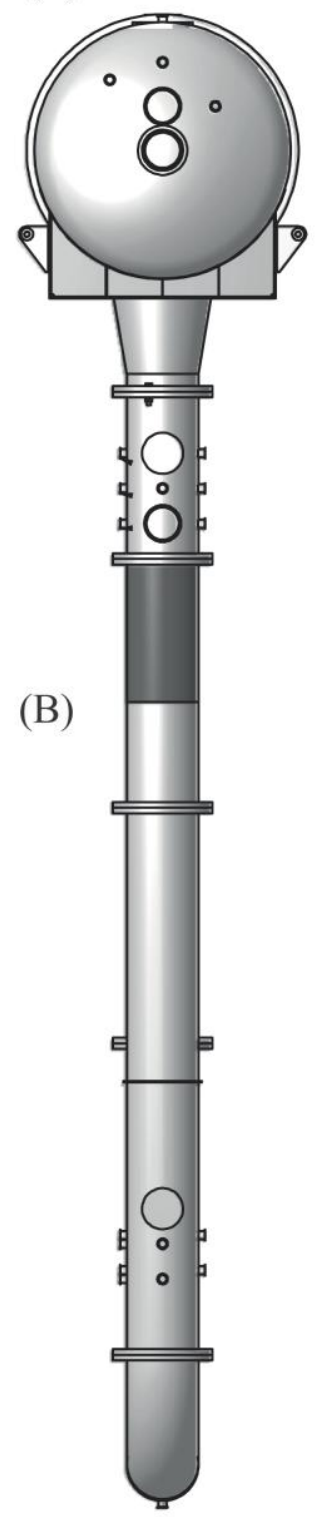

(5)

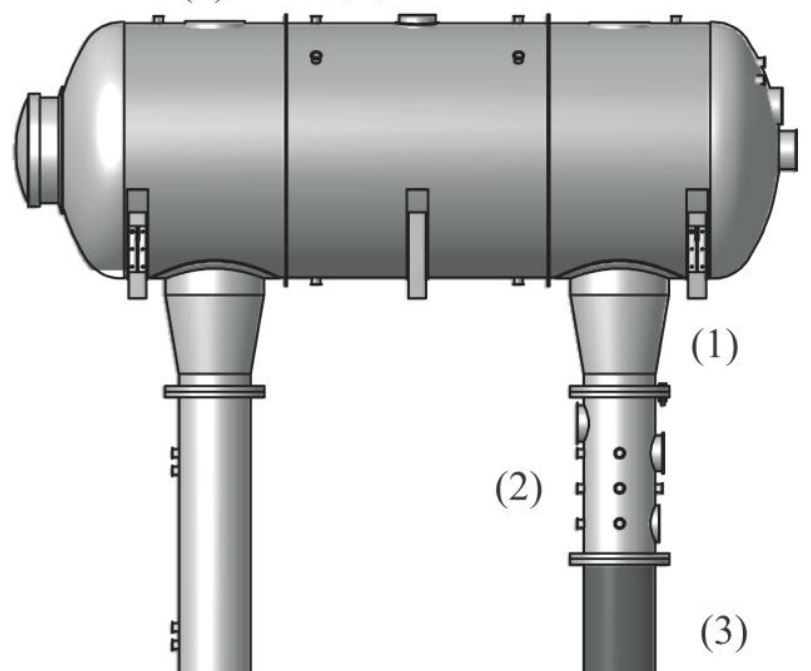

(4)

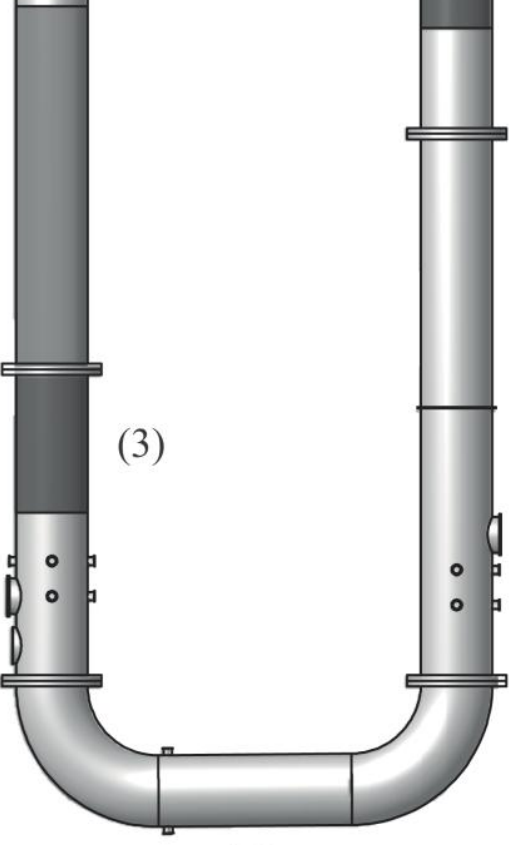

(B)

Figure 1 


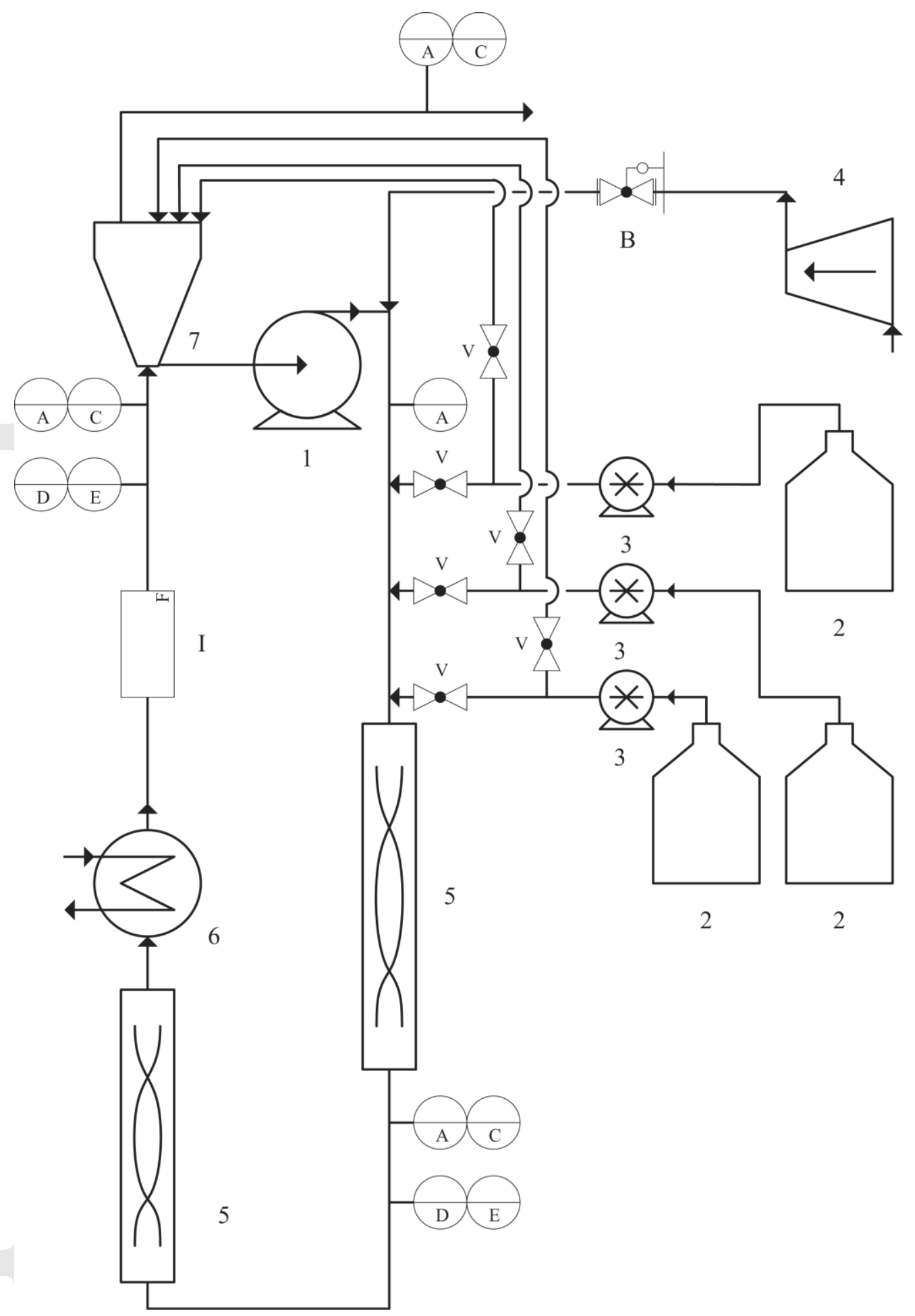

Figure 2 

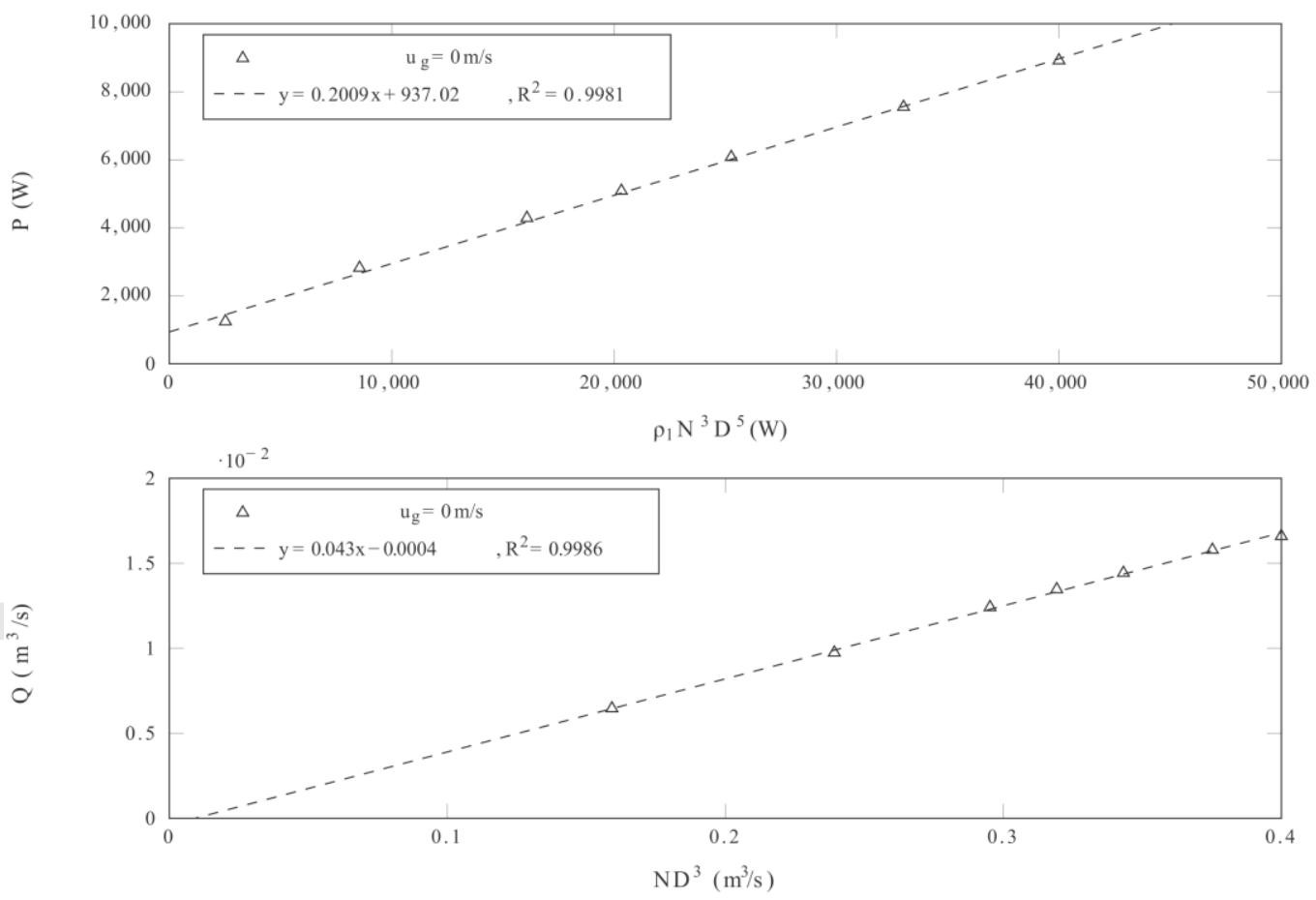

Figure 3

This article is protected by copyright. All rights reserved 


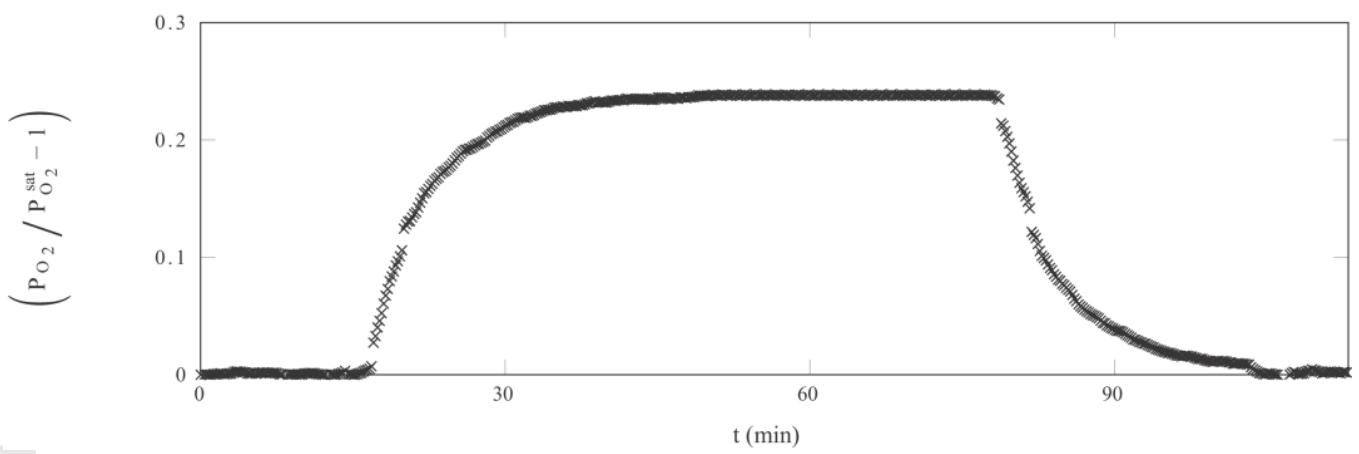

Figure 4

This article is protected by copyright. All rights reserved 


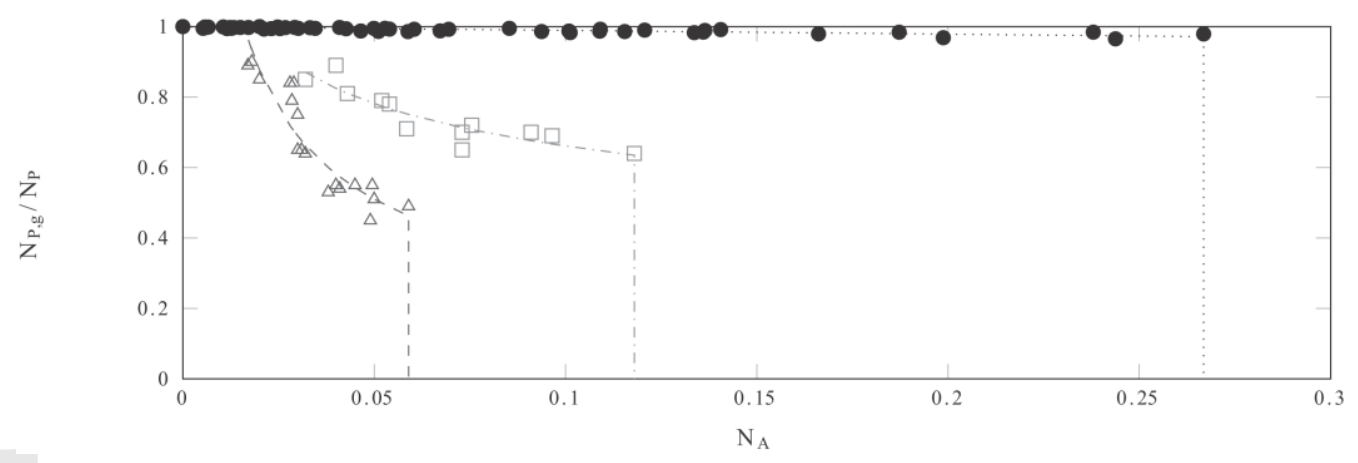

Figure 5

This article is protected by copyright. All rights reserved 

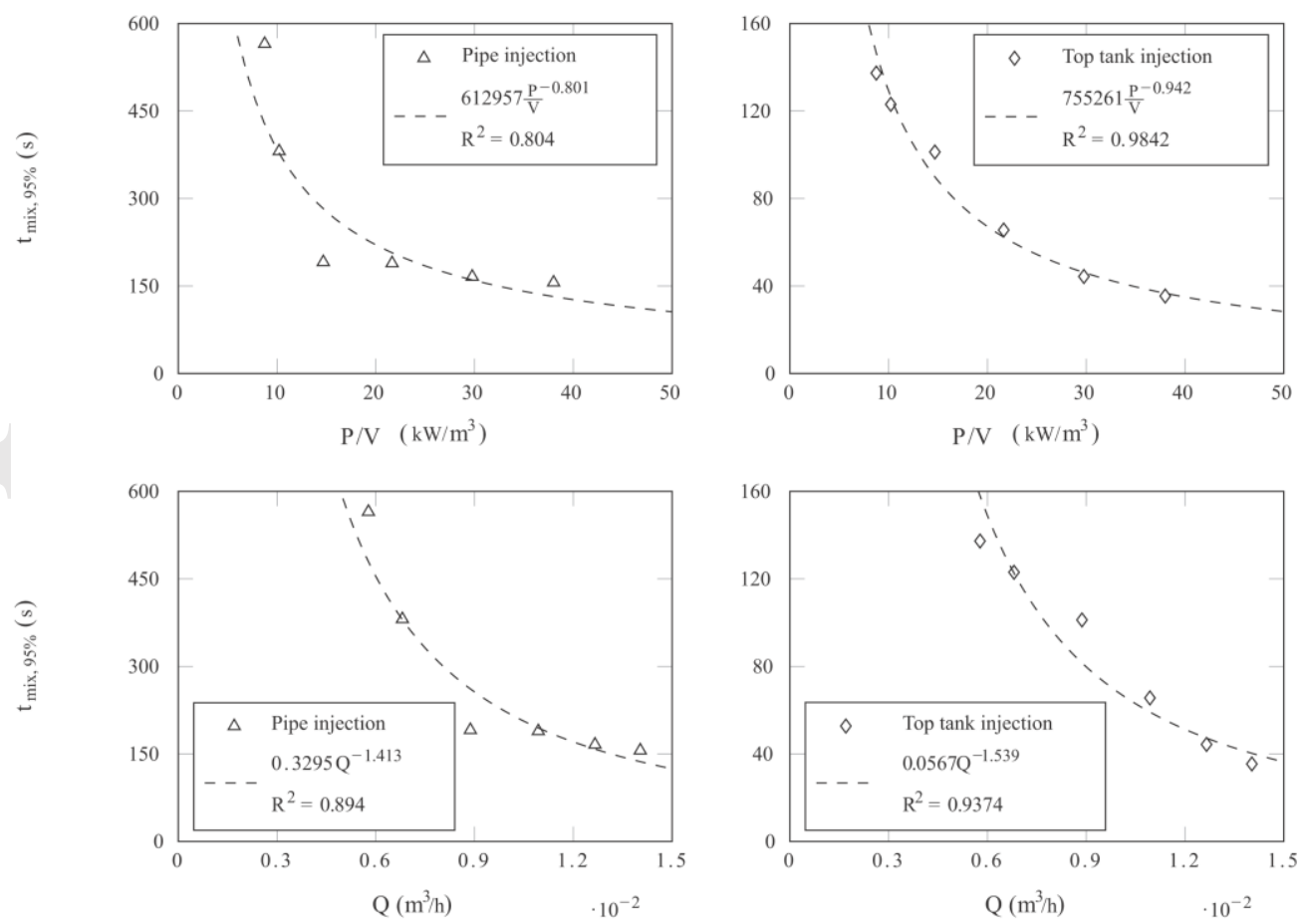

Figure 6 

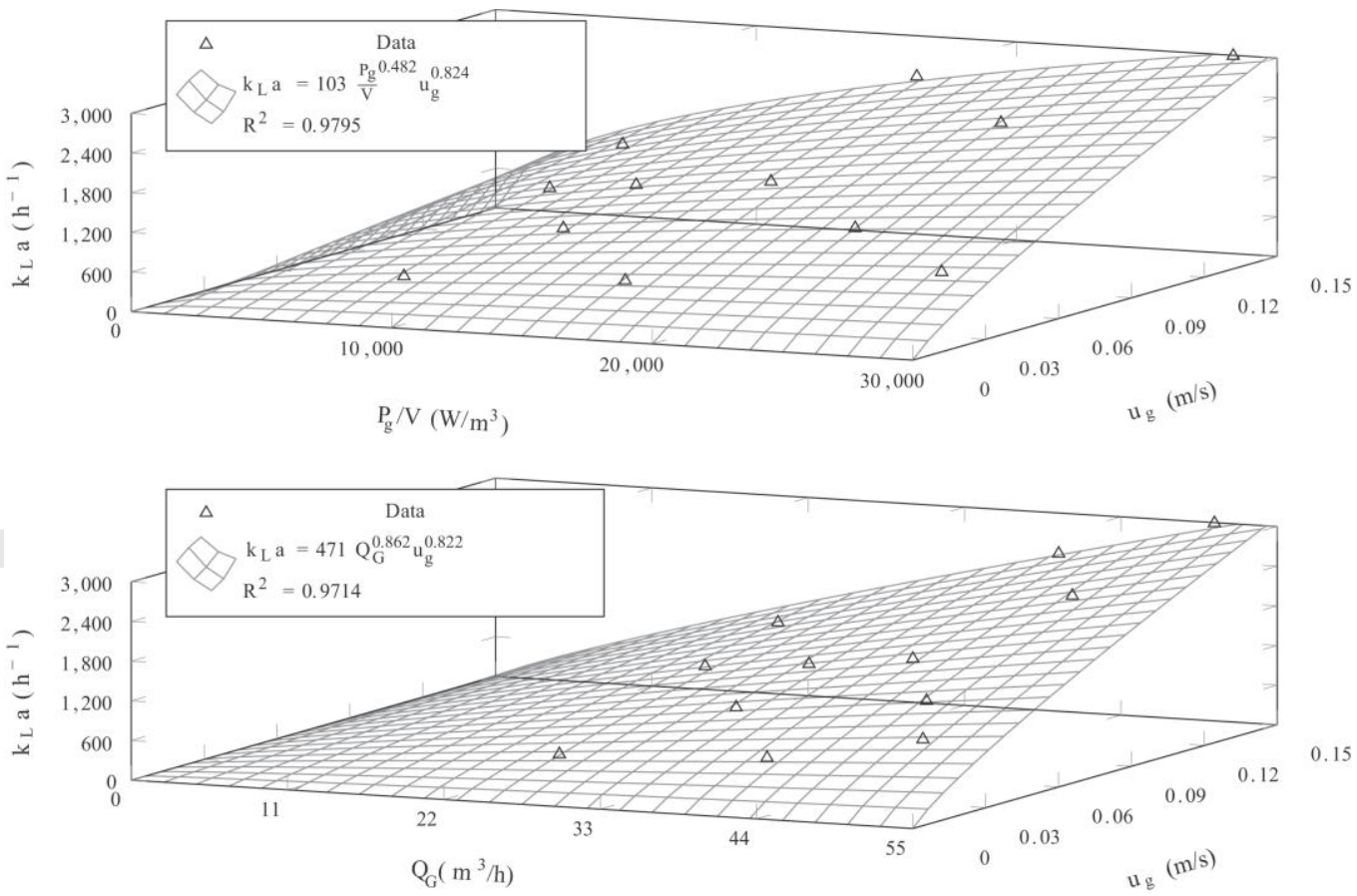

Figure 7

This article is protected by copyright. All rights reserved 

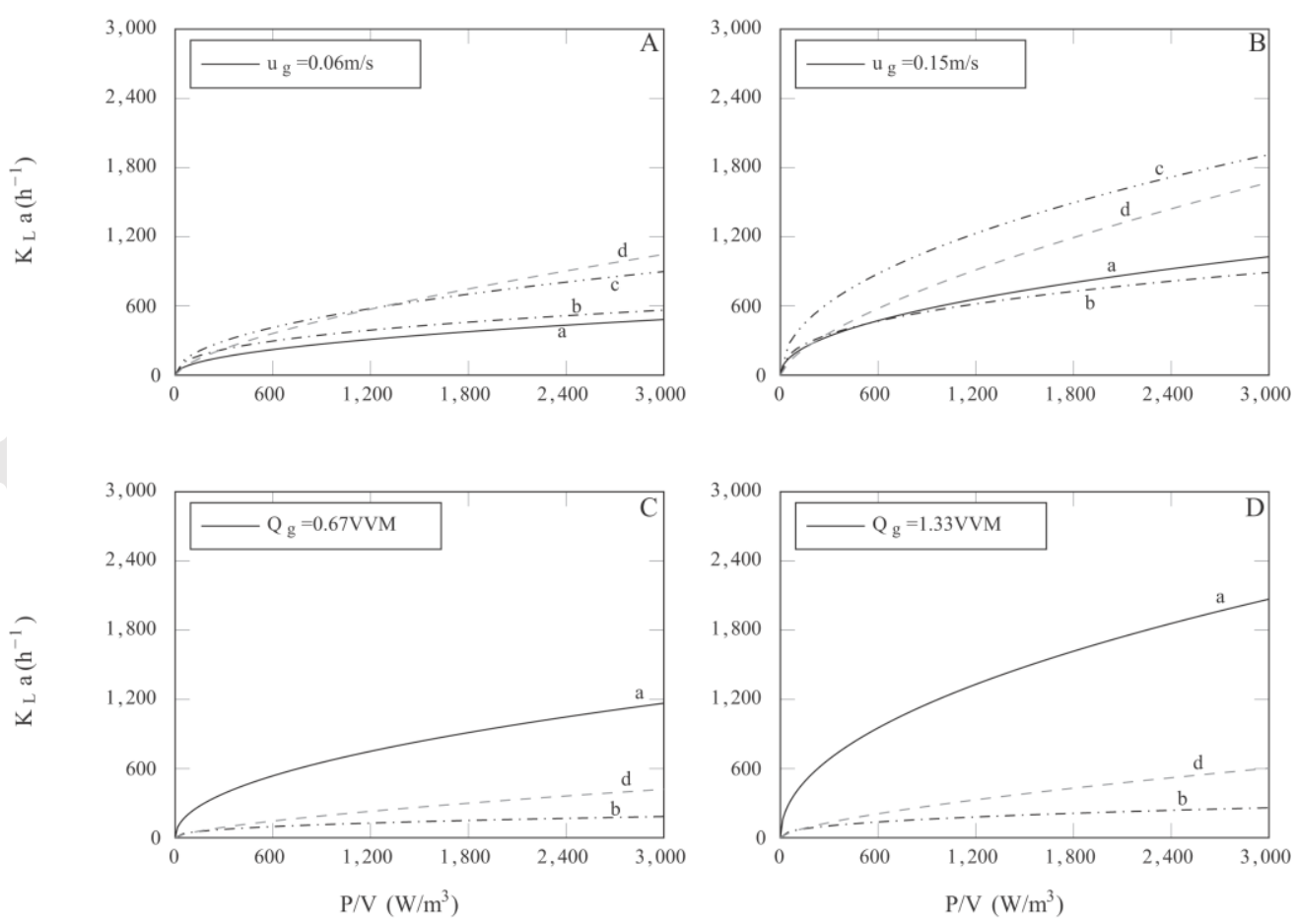

Figure 8 

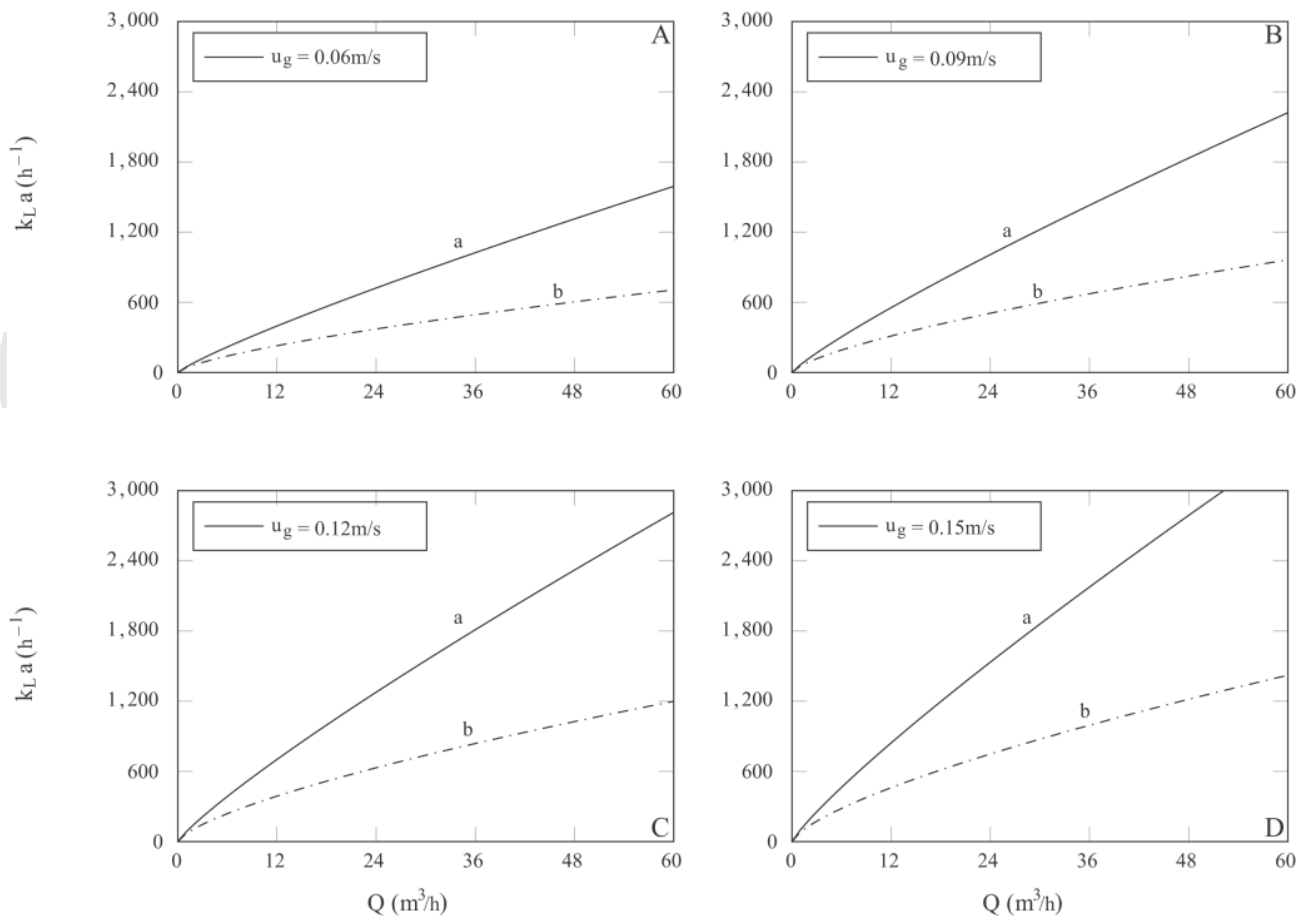

Figure 9

This article is protected by copyright. All rights reserved 